\title{
Economic assessment of the control of human- factor impact on faults of technical facilities in railway-transport technological processes
}

\author{
Valery Vorobyov ${ }^{1, *}$, Aleksey Manakov ${ }^{1}$, and Irina Repina $^{1}$ \\ ${ }^{1}$ Siberian Transport University, 630049, Novosibirsk, Russia, Dusi Kovalchuk st., 191
}

\begin{abstract}
In the present paper, we substantiate the necessity of control and economic assessment of the human-factor (HF) impact on faults of technical facilities in railway-transport technological processes. An algorithm for calculating the economy due to the reduction of losses caused by railwayinfrastructure faults is proposed; this algorithm is based on the calculation of the losses versus the quantity and duration of the related faults.
\end{abstract}

\section{Introduction}

Railways remain a leading member of the world transport system. Many countries implement programs of unprecedented scope for improving the railway infrastructure aimed at reaching a significant increase of transportation volumes on both internal and external routes. In the Czech Republic, railway-infrastructure modernization activities are implemented within the four-corridor approach ensuring the railway communication with Germany, Poland, and Austria [1]. Transport projects under implementation in Paris areas supplement the dense public-transport network with railway transport systems which connect the city with nearby regions [2]. The plan of restoration of railways in Romania implies making investments for radical improvement of railway conditions in the country [3]. Thailand considers the investments into railway-infrastructure improvement as a most efficient way toward solving logistics problems [4]. The program of railway development in Germany in force till 2030 is intended for ensuring a stable growth of passenger and goods transportation by long-distance trains [5].

The railway industry in many countries, including Russia, involves elements of the postindustrial economy model. Simultaneously, the new paradigm of scientific-knowledge development poses the integrity problem for the understanding of new notions, categories, methods and principles of organizational changes of transport systems in space and time. Among the involved problems, the most urgent ones are the problems of technical and organizational-technological reliability of railway-transport technological processes. Statistical studies have revealed significant time losses occurring during implementation of production processes and, hence, economic losses due to insufficiently efficient productionprocess organization and human factor (HF) $[6,7,8]$. Measures under development in the infrastructure divisions of railways toward HF-impact reduction are often non-regular, and

* Corresponding author: decansgd@stu.ru 
they are mainly aimed at the prevention and mitigation of accidents. The systematic approach to the solution of involved problems proved to be unsatisfactory due to the poorly developed HF control and management methodology $[9,10,11]$. A number of reported studies on the informational support, resource and reliability management, and risk control at life-cycle stages suggest certain specification of machine-fault records $[13,14,15]$. Simultaneously, further improvement of assessment methods for the economic losses from HF-induced negative events still presents an urgent task.

\section{Materials and Methods}

The duration of the $i$-th negative event (NE), $t_{i}{ }^{N E}$, includes the time $t_{i}^{f i}$ to be spent on the identification of the failure which has inflicted the accident, the time $t_{i}^{\text {rep }}$ required for the repair, and the unproductively wasted time $t_{i}^{w}$ :

$$
t_{i}^{N E}=t_{i}^{f i}+t_{i}^{r e p}+t_{i}^{w}
$$

The sum of the time losses due to the failures within a planned period (month, quarter or year) will amounts to $t_{P}^{H G}$ :

where

$$
\begin{gathered}
t_{P}^{H G}=\sum_{\substack{i=1 \\
t_{i}}}^{m} t_{i}^{H C} \\
t_{i}^{N E}+t_{i}^{r e p}+t_{i}^{w},
\end{gathered}
$$

$t_{i}^{N E}$ is the duration of the $i$-th negative event,

$t_{i}^{f i}$ is the time to be spent on failure identification,

$t_{i}^{r e p}$ is the time required for the repair,

$t_{i}^{w}$ is the unproductively wasted time.

The total number of machine faults is $m=m_{(1)}+m_{(2)}+m_{(\Psi \Phi) \text {, }}$

where

$m_{(1)}$ is the amount of category- 1 machine faults;

$m_{(2)}$ is the amount of category-1 machine faults;

$m_{(H F)}$ is the amount of machine faults due to the human factor.

The total duration of the failures is

$$
t_{P}^{H G}=\sum_{i=1}^{m_{(1)}} t_{i}^{\mathrm{HC}_{(1)}}+\sum_{i=1}^{m_{(2)}} t_{i}^{H C_{(2)}}+\sum_{i=1}^{m_{(C F)}} t_{i}^{H C_{(C F)}}
$$

The expanses for the elimination of the consequences of one negative event involve the following contributions:

$C_{i}^{(M)}$ are the expenses for the materials, structural elements and other material and technical resources per unit time;

$C_{i}^{(L)}$ are the labor costs for the repair, etc. (elimination of negative-event consequences) per unit time;

$C_{i}^{(O)}$ are all other expenses per unit time.

$$
\begin{gathered}
C_{i}=C_{i}^{(M)}+C_{i}^{(L)}+C_{i}^{(O)} \\
C_{i}=C_{i}^{(I)}+C_{i}^{(2)}+C_{i}^{(H F)} \\
C_{i}^{N E}=C_{i} \cdot t_{i}^{N E}=C_{i}^{(I)} \cdot t_{i}^{N E(1)}+C_{i}^{(2)} \cdot t_{i}^{N E(2)}+C_{i}^{(H F)} \cdot t_{i}^{N E(H F)}
\end{gathered}
$$

The total expenses within the period are

$$
\mathrm{C}_{P}^{H C}=\sum_{i=1}^{m} C_{i} \cdot t_{P}^{H C}=t_{P}^{H C} \cdot \sum_{i=1}^{m} C_{i}=\sum_{i=1}^{m_{(1)}} C_{i}^{(1)} t_{i}^{(1)}+\sum_{i=1}^{m_{(2)}} C_{i}^{(2)} t_{i}^{(2)}+\sum_{i=1}^{m_{(C F)}} C_{i}^{(C F)} t_{i}^{(C F)}
$$


The average costs $(\overline{\mathrm{C}})$ at average fault duration required for elimination of negative-event consequences $(\bar{t})$ are

$$
\mathrm{C}_{P}^{H C}=\overline{\mathrm{C}^{(1)}} \cdot m_{(1)} \overline{t^{(1)}}+\overline{\mathrm{C}^{(2)}} \cdot m_{(2)} \overline{t^{(2)}}+\overline{\mathrm{C}^{(C F)}} \cdot m_{(C F)} \overline{t^{(C F)}}
$$

The probability for the total amount of negative events (faults) to remain lower than some limiting value is

$$
P\left(m \leq m_{3}\right)=\frac{1}{\sqrt{2 \pi} \sigma} \int_{0}^{m_{3}} e^{-\frac{m-\bar{m}}{2 \sigma^{2}}} d m
$$

Then, we have:

$$
C_{P}{ }^{N E}=\overline{\mathrm{C}}^{(l)} \cdot m_{(1) 3} \cdot P_{(1)} \cdot t_{P}^{(l)}+\overline{\mathrm{C}}^{(2)} \cdot m_{(2)_{3}} \cdot P_{(2)} \cdot t_{P}^{(2)}+\overline{\mathrm{C}}^{(H F)} \cdot m_{(H F)_{3}} \cdot P_{(H F)} \cdot t_{P}^{(H F)},
$$

where $P_{(I)}, P_{(2)}$, and $P_{(H F)}$ are the occurrence probabilities of a given number of category-1 and category-2 negative events/faults, and the occurrence probability of negative events due to human factors, respectively; and

$t_{P}{ }^{(1)}, t_{P}{ }^{(2)}$, and $t_{P}^{(H F)}$ are respectively the calculated values of time losses due to a negative event of the $1^{\text {st }}$ and $2^{\text {nd }}$ categories and due to the human factor.

The distribution probabilities of machine faults at the West Siberian railway caused by human factors and defining the risks are shown in Fig. $1[8,12]$.

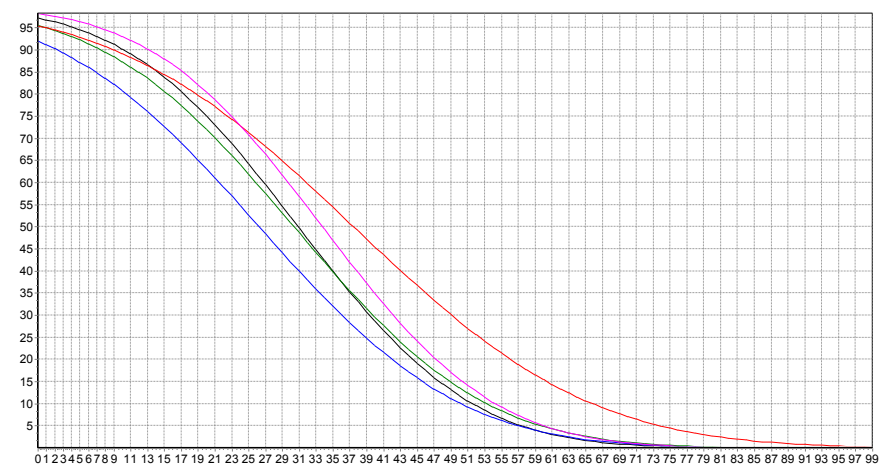

Fig. 3. The distribution probabilities of HF-induced machine faults at the West Siberian railway.

The faults involving the behavioral factor and expressed in the workers' personal traits are shown in black color; the faults involving the maintenance factors and expressed in the personnel selection, experience background, and knowledge of railway systems, in blue color; the faults related with equipment design, in green color; the faults related with the data collection and transfer, and manifested as a wrong interpretation of oral messages and insufficient coordination of personnel activities, in red color; and the faults related with a subjective perception of the environment and a subjective response to its manifestation, in purple color.

The costs, or damages, due to the human factor can be estimated by the formula

$$
C^{H F}=m_{(H F)_{3}} \cdot P_{P}^{(H F)} \cdot t_{P}^{(H F)}
$$

The reduction in the amount of negative events/faults, $m_{\text {exp }}$, by $\Delta m$ can then be calculated as

$$
M_{\text {exp }}=m_{(H F)_{3}}-\Delta m .
$$


As a result, the reliability, or the probability of a situation in which the amount of negative events will remain lower than $m_{\exp }$, will increase in value:

$$
C_{\text {exp }}{ }^{H F}=m_{(H F) \exp } \cdot P_{\exp }{ }^{(H F)} \cdot t_{P \exp }{ }^{(H F)},
$$

and the savings due to the reduction of damages will amount to

$$
\Delta C^{(H F)}=C^{(H F)}-C_{\text {exp }}^{(H F)} .
$$

Control of the human factor is a continuous process of improvement and development of labor-management relations whose efficiency is largely determined by the feedback system which includes the supervision and tracking the results, personnel's opinions, and the effectiveness of the personnel-training program, and the program of practical tasks for the divisions.

The main principles to be adhered to while taking into account the HF impact are the following:

1. The reduction of the HF impact on the faults of technical systems requires some modification of human behavior during a substantiated time interval within the framework of the corporate management concept of JSC Rossiiskie Zheleznye Dorogi (RZhD).

2. The HF impact is to be evaluated by competent authorities at regional corporate management centers (RCMC) of railways.

3. Encouragement of the divisions' efficient activities enables correct human behavior.

4. Creation of conditions for personnel's regular practice enhances the organizational and technological reliability in the industry.

5. Human factor management is an industry organization and staff's collective-behavior norm rather than an emergency procedure.

We consider it appropriate to give here a brief characteristic of the Dao Toyota principles as applied to railway industry organization.

Principle 1. Managerial decision-making process in the structural subdivisions of JSC $\mathrm{RZhD}$ Directorate must proceed with regard for long-term prospects even if this procedure runs counter to short-term financial objectives.

Principle 2. The Lean Production process must be implemented as an uninterrupted flow with identification of potential problems.

Principle 3. In implementation of industry organization functions, a uniform distribution of work volume must be observed.

Principle 4. Solution of industrial problems must proceed as part of the industry culture, which practice promotes the quality improvement process.

Principle 5. The continuous improvement based on the execution of standard tasks and on the reduction of HF impact must be an adhered practice.

Principle 6. Visual control must be executed to exclude unnoticed problems.

Principle 7. Only approbated reliable technologies must be adopted.

Principle 8. Upbringing of leaders, creation of organization value, and the use of company philosophy must be adhered to as common practices.

Principle 9. Upbringing of outstanding workers and forming of a team that uses the company philosophy must be implemented.

Principle 10. The suppliers and partners are to be treated with due respect, as colleagues enjoying equal rights.

Principle 11. Original vision of the various situations (seeing everything with one's own eyes, according to the Genchi Genbutsu principle) must be generated.

Principle 12. Consensus-based decisions must be taken without hurry after the rational assessment of all possible options with subsequent immediate implementation (nemavasi).

Principle 13. A self-teaching system based on diligent self-analysis (hansay) and continuous self-improvement (keisen) must be established. 


\section{Results}

Like the problem of diminishing the HF impact on the industrial process, the implementation of the above principles is not a one-minute task easy to accomplish. This area requires persistent efforts to be applied with allowance for the mentality of those people who implement production processes at railways.

With the aim of more particular specification of the economic assessment of measures toward HF-impact reduction, the present paper identifies four such measures listed below:

- individual and collective maintenance and repair training of personnel (measure S1);

- creation of organizational conditions that strengthen the stability of the acquired skills using the systematic account of psychophysiological human capacities and restrictions. The expenses will amount to Eorg (measure S2);

- development and implementation of prophylactic measures to identify the main causes of hazardous situations resulting from the HF impact. The expenses will amount to Epr (measure S3);

- introduction of the process approach within the framework of the corporate management concept of JSC RZhD. The expenses will amount to EPA (measure S4).

Supplementary measure S5, S5=S1US2US3US4, in which all the above measures are combined in a certain proportion and the following optimization methods are applied:

- $\quad$ the optimal solution according to Wald's maximin criterion; and

- the optimal solutions according to the optimism and pessimism criteria.

The expected-efficiency values due to the introduction of HF-impact reduction measures are given in Table 1.

Table 2. The expected-efficiency values due to the introduction of HF-impact reduction measures

\begin{tabular}{|l|l|l|l|l|l|}
\hline \multirow{2}{*}{$\begin{array}{c}\text { Efficiency expected } €, \\
\text { thousand rubles }\end{array}$} & \multicolumn{5}{|c|}{ Measures } \\
\cline { 2 - 6 } & S1 & S2 & S3 & S4 & S5 \\
\hline E1 $=8,000$ & 140 & 220 & 150 & 3,200 & 3,710 \\
\hline E2 $=50,000$ & 220 & 320 & 150 & 5,800 & 6,490 \\
\hline E3 $=90,000$ & 250 & 350 & 150 & 15,000 & 15,750 \\
\hline
\end{tabular}

The benefit values are $B_{i j}=E_{k} / S_{i} ; K=\overline{1,3}$; and $\left.S_{i}=\overline{1,4}\right)$. The expected-benefit values due to the introduction of HF-impact reduction measures are given in Table 2.

Table 2. The expected benefit due to the introduction of HF-impact reduction measures

\begin{tabular}{|l|l|l|l|l|l|}
\hline \multirow{2}{*}{$\begin{array}{c}\text { Benefit expected (B), thousand } \\
\text { rubles }\end{array}$} & \multicolumn{5}{|c|}{ Measures } \\
\cline { 2 - 7 } & S1 & S2 & S3 & S4 & S5 \\
\hline B1=8 000 & 7,14 & 5,36 & 3,33 & 2,5 & 0,16 \\
\hline B2=50 000 & 227,27 & 156,25 & 333,3 & 8,62 & 7,70 \\
\hline B3 $=90000$ & 360,0 & 257,14 & 600,0 & 6,0 & 5,71 \\
\hline
\end{tabular}

1. Wald's criterion of the guaranteed result

$$
E_{G}=\max \min B_{i j}
$$

According to the algorithm, we choose the minimum values in each line:

The maximum value is 7.17 .

$$
\min =\left\{\begin{array}{l}
0,16 \\
7,17 \\
5,17
\end{array}\right\}
$$

The maximum value from among the minimum values corresponds to the expected efficiency amounting to 50 million rubles. According to Wald's criterion, preference should 
be given to E2, with the total expenses being equal to 6,490 thousand rubles in the case of the strategy S5 being implemented.

2. Pessimism criterion

$$
\begin{gathered}
E_{G}=\min \min \left\{B_{i j}\right\} \\
\min =\left\{\begin{array}{l}
0,16 \\
7,17 \\
5,17
\end{array}\right\} \min =0,16
\end{gathered}
$$

The total expenses for this criterion will amount to 3,710 thousand rubles, the expected efficiency being 80,000 thousand rubles according to the strategy S5.

3. Optimism criterion

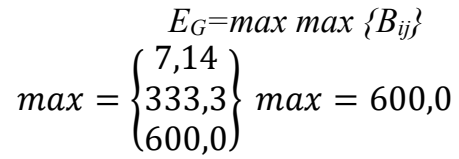

This case corresponds to the expenses according to the strategy S3 and to the expected efficiency amounting to 90,000 thousand rubles. In case of a third-party contractor being engaged or in case of the work being performed by own efforts at objects financed through investments or capital repair, we propose using a classical approach employing the standard investment efficiency assessment method (Table 3). The performed study has allowed us to develop a new "Method of identification and control of the human-factor impact on the

\begin{tabular}{|c|c|c|c|c|c|c|c|c|c|c|c|c|}
\hline Indicators & 0 & 1 & 2 & 3 & 4 & 5 & 6 & 7 & 8 & 9 & 10 & Total \\
\hline \multicolumn{13}{|l|}{ Operating activity } \\
\hline \multicolumn{13}{|l|}{ Cash inflow } \\
\hline $\begin{array}{l}1 \text { Reduction of current } \\
\text { expenses }\end{array}$ & & 2232 & 2232 & 2232 & 2232 & 2232 & 2232 & 2232 & 2232 & 2232 & 2232 & 22323 \\
\hline $\begin{array}{l}2 \text { Depreciation } \\
\text { deductions }\end{array}$ & & 132,5 & 132,5 & 132,5 & 132,5 & 132,5 & 132,5 & 132,5 & 132,5 & 132,5 & 132,5 & 1325 \\
\hline \multicolumn{13}{|l|}{ Cash outflow } \\
\hline 4 Property tax & & 45,0 & 45,0 & 45,0 & 45,0 & 45,0 & 45,0 & 45,0 & 45,0 & 45,0 & 45,0 & 450,5 \\
\hline 5 Tax on profit & & 411,0 & 411,0 & 411,0 & 411,0 & 411,0 & 411,0 & 411,0 & 411,0 & 411,0 & 411,0 & 4109,5 \\
\hline \multicolumn{13}{|l|}{ Investment activity } \\
\hline \multicolumn{13}{|l|}{ Cash outflow } \\
\hline $\begin{array}{l}\text { 9. Net discounted } \\
\text { income }\end{array}$ & -2100 & 1735,004 & 1577,524 & 1434,113 & 1303,739 & 1185,217 & 1077,47 & 979,5182 & 890,4711 & 809,5192 & 735,9265 & 9628,501 \\
\hline $\begin{array}{l}9.1 \text { Net discounted } \\
\text { income running total }\end{array}$ & -2100 & $-364,996$ & 1212,528 & 2646,64 & 3950,379 & 5135,596 & 6213,066 & 7192,584 & 8083,055 & 8892,574 & 9628,501 & \\
\hline Discount rate, $\%$ & & & & & & 10 & & & & & & \\
\hline Discount factor & 1 & 0,909 & 0,826 & 0,751 & 0,683 & 0,621 & 0,564 & 0,513 & 0,467 & 0,424 & 0,386 & \\
\hline
\end{tabular}
organizational and technological production reliability".

Table 3. Calculation of investment-efficiency indicators

\section{Conclusions}

Further scientific and practical research into the development of industry organization methods due to taking into account the human factor at railway transport must be aimed at the creation of an HF management system; at the development of a control system for the flow of HF-induced machine faults; and at the adaptation of world leading companies' management experience for the purpose of taking into account the HF impact on the organizational and technological reliability of railway-transport technological systems. 


\section{References}

1. Railway Modernization Program in the Czech Republic, Zheleznye Dorogi Mira, 1, 13 - 16 (2016)

2. URL: www.ixpos.de

3. URL: ec.europa.eu

4. URL: ec.europa.eu

5. Development Program of Passenger Traffic on Railways in Germany / Zheleznye Dorogi Mira, 12, 17 - 21 (2016)

6. V. Vorobiev, Collection of SWorld Scientific Papers written by the Materials of the International Academic Conference Scientific Research and its Practical Application. Current State and Development Routes. 3,2, 32 - 38 (2012)

7. V.S. Vorobiev, Nauka i Transport. 3. 42 - 46 (2012)

8. I.B. Repina, $\mathrm{PhD}$ Thesis (2015)

9. J.-M. Hiltrop, A framework for diagnosing human resource management practices (Europ. Management, Oxford, 1996)

10. URL: https://www.osp.ru/cio/2000/06/170900

11. S. Egorov, Voprosy Ekonomiki, 5. 85 - 97 (2014)

12. I.B. Repina, Nauchnye Problemy Transporta Sibiri i Dal'nego Vostoka. 1. $114-117$ (2013)

13. E.N. Rosenberg, I.N. Rosenberg, A.M. Zamyshlyaev, G.B. Proshin, Zheleznodorozhnyi Transport, 9, 6-16 (2008)

14. JSC RZhD Standard "Management of Resources at Life-Cycle Stages, Control of Risks, and Analysis of Reliability (MRCRAR). Systems, Devices and Equipment of Automatics and Remote-Control Facilities. Requirements of Reliability and Functional Safety. RZhD Standard 02.042-2011

15. JSC RZhD Standard 02.044-2011. Management of Resources, Control of Risks, and Analysis of Reliability at Life-Cycle Stages (MRCRAR). Terms and Definitions, Moscow, JSC RZhD 